\title{
Prenatal and post-hatch assessment of two strains of broiler chickens reared under high natural ambient temperatures
}

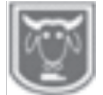

Tanimowo, D. A., Adesanya, S. and Longe, O. G.

Department of Animal Science, University of Ibadan, Nigeria

Corresponding author: damilolatanimowo@yahoo.com

Abstract

Pre-natal (PN) and post-hatch (PH) assessments were carried out on two broiler chicken strains to examine possible origin of strain differences and response to heat stress. One hundred and forty fertile eggs incubated for 18 days as PN and 192 day-old broiler chicks as PH; were evenly divided between two strains (Arbor Acres [AA] and Marshal [MS]). For the $P N$ assessment (day 18, 19 and 21 of incubation), embryos were dissected and organs weighed. Liver glycogen and moisture content of the carcass and residual yolk sac were also determined. Post hatch, average body weight (ABW), average daily feed intake (ADFI) and feed conversion ratio (FCR) were measured under high natural ambient temperatures. At d 18 of incubation, proportional breast weight and yolk moisture was higher in AA than MS (P $<0.05)$, with the same trend observed at 21 for yolk weight (\%). Breast, gizzard, heart and liver weights were observed to increase linearly, in proportion to weight of embryo $(P<$ 0.001), between 18 and 21 on incubation, while the inverse was observed for yolk weight (\%). Post-hatch, ADFI and FCR at the end of the starter phase were lower in MS compared with AA $(P<0.05)$. However, at the end of the finisher phase, only ADFI was significantly influenced by strain of broiler $(A A<M S ; P<0.05)$. Serum electrolytes and carcass characteristics did not differ between strains $(P>0.05)$. Phenotype differences in were manifested prior to hatch, with Marshall exhibiting advantage to Arbor Acres under high ambient temperatures.

Keywords: Heat stress, organ weights, broiler embryo, genotype, growth performance

\section{Introduction}

There is an improvement in the potential of broiler chicken strains to provide high quality meat at lower cost (Kemp and Kenny, 2003). A significant proportion of these birds are however, required to perform outside their optimal environment; as found mainly in tropical regions. They are thus, subjected to varying levels of environmentally induced stress. Heat stress results from a negative balance between the amount of heat energy produced by an animal and the net amount of energy flowing from the animal's body to its surrounding environment. Thermal stress can be either acute or chronic. Acute stress occurs when ambient temperature increases drastically for a short time (no more than a few days; Cahaner et al., 1996).
Chronic heat stress is induced by cyclic or continuous high environmental temperatures over a long period (days to weeks), permitting acclimatization to the environment (Lozano et al., 2006). Chronic heat stress has detrimental effects on the performance of broiler birds reared in opensided poultry houses; principally through reducing feed intake, growth rate, feed efficiency and carcass quality (Har et al., 2000). In addition, prolonged periods of elevated ambient temperature increase the time to reach market weight as well as mortality (Abdur-Rahmanet al., 2007). Living organisms respond to changes in environmental temperature by activation of physiological mechanisms involved in the loss or production of heat. Inability to react or adapt to these environmental changes 


\section{Pre-natal development and genotype differences in broilers}

may compromised homeostasis and even lead to death (Guerreiro et al., 2004). Many poultry researchers now realize that future gains in genetic and production potential of poultry will come from advancement made during incubation period and embryogenesis (Christensen et al., 2007). Previous scientists have examined relationships of the physiological characteristics of broilers within the embryonic or post-hatch periods. For instance, the chicken embryonic liver has been established as pivotal to maintaining energy homeostasis, cell division, signal transduction, organogenesis, and other essential functions during embryo development and growth (Jianzhen et al., 2007; De Oliveira et al., 2008). Also embryos depend on yolk lipids for energy production, with more than $90 \%$ of the embryonic energy requirement provided for by yolk lipids (Speake et al., 1998). It has been shown that anything that influences growth and development during incubation period will significantly affect overall growth performance and health of modern strains of meat poultry (De Oliveira et al., 2008). It has been suggested that modern poultry genotypes produce more body heat, due to their greater metabolic activity. Understanding and controlling environmental conditions is crucial to successful poultry production and welfare. The current study, on the other hand, makes a further effort to examine these relationships across the embryonic, hatch, and post-hatch periods on the basis of their specific egg of origin and also provide basic information to design further experiments to find means of alleviation of heat stress under high ambient temperature conditions. Thus the objective of this study is to assess perinatal and post-hatch performance and heat stress tolerance between to two strains of broiler chicken.

\section{Materials and methods}

Pre-hatch assessment was conducted on 140 fertile (18days of incubation) broiler chicken eggs, while 192, one day-old broiler chicks were used for the post-hatch and heat tolerance assessment. The total number was evenly divided between two strains: Arbor Acres and Marshall. The broilers were purchased from a hatchery in Ibadan, Oyo State.

\section{Pre-hatch assessment}

On the $18^{\text {th }}$ day of incubation, eggs were weighed and representative eggs were broken. The embryos were weighed, dissected and various organs weighed. Samples of the liver and breast muscles were excised and placed in $10 \%$ perchloric acid and stored at $-20^{\circ} \mathrm{C}$ until analyzed for glycogen according to the PHESUL method of Bennett et al. (2007). The embryo carcasses and residual yolk sacs were oven dried to constant weight at $85^{\circ} \mathrm{C}$ to determine moisture content. Pre-hatch parameters were carried out on days 18, 19 and 21 of incubation.

\section{Post-hatch assessment}

On arrival from the hatchery, chicks were tagged, weighed and distributed to 8 replicate pens per broiler chicken strain. The chicks were raised on deep litter and provided feed (maize-soybean meal based diet; Table 1) and water ad libitum. On a weekly basis, average daily gain and average daily feed intake were recorded and feed conversion ratio calculated. In addition, from the $4^{\text {th }}$ week, water intake was recorded daily up to the end of the experiment. At the starter and finisher phases, blood $(3 \mathrm{~mL})$ was collected from the jugular veins of representative birds into sterile tubes, centrifuged at 3000rpm for $15 \mathrm{mins}$ and serum electrolytes assayed using respective kits; $\mathrm{Na}^{+}$(Teco Diagnostics, California), $\mathrm{Cl}^{-}$(Teco Diagnostics, California) and $\mathrm{K}^{+}$(Atlas 


\section{Tanimowo, Adesanya and Longe}

Medicals, Cambridge). At the end of the starter and finisher phases, representative birds were slaughtered, eviscerated and organs removed and weighed. Throughout the experimental period, birds were exposed to natural ambient conditions, with temperatures in the experimental pen recorded daily and aggregated on a weekly basis (average temperatures were: minimum - $25.9 \pm 1.0^{\circ} \mathrm{C}$ and maximum $35.4 \pm 2.0^{\circ} \mathrm{C}$ ).

\section{Statistical analysis}

Data between strains from the pre-natal and post-hatch assessments were analysed using independent sample T-test of SPSS version 20.0.0. Pre-hatch data within strains were tested by one-way ANOVA, while effects of pre-natal days were tested with polynomial contrasts.

\section{Results}

\section{Pre-hatch assessment}

Mean values for relative organ weights of broiler chicks at days 18, 19 and 21 of incubation are presented in Table 1. On day
18 of incubation, no significant differences were observed for chick weight, relative weights of gizzard, heart, liver and yolk sac. However relative breast weight was significantly higher in AA than MS $(P<$ 0.05). On day 19 of incubation, no significant differences were observed for chick weight and relative weights of organs. Also by day 21 , chick weight and relative weights of breast, gizzard, heart and liver did not exhibit any significant difference between the broiler chicken strains. Relative yolk sac weight was however lower for MS compared with AA $(P<0.05)$. Polynomial contrasts highlighted linear reduction in chick weight from day 18-21 of incubation $(P<0.001)$. Relative weights of breast, gizzard, heart and liver in both AA and MS were observed to increase with days, up to $\mathrm{d} 21$ of incubation $(P<0.001$ respectively). On the other hand, weight of yolk relative to chick weight exhibited a linear decrease $(P<0.001)$ in both strains from d 18 to 21 of incubation.

Table 1: Relative organ weights of Arbor Acres and Marshall chicks prior to hatch

\begin{tabular}{|c|c|c|c|c|c|c|}
\hline & & Days $^{1}$ & & & Contras & \\
\hline & Strain & $18-d$ & $19-d$ & $21-d$ & Lin & Qua \\
\hline Chick wt (g) & Arbor Acres & $48.9 \pm 0.92^{x}$ & $45.8 \pm 0.55^{y}$ & $40.0 \pm 0.46^{z}$ & $<0.001$ & 0.202 \\
\hline & Marshall & $47.7 \pm 0.84^{x}$ & $45.4 \pm 1.44^{x}$ & $40.9 \pm 0.75^{\mathrm{y}}$ & $<0.001$ & 0.415 \\
\hline Heart $(\%)$ & Arbor Acres & $0.54 \pm 0.024^{y}$ & $0.63 \pm 0.043^{y}$ & $0.85 \pm 0.024^{x}$ & $<0.001$ & 0.113 \\
\hline & Marshall & $0.56 \pm 0.016^{y}$ & $0.61 \pm 0.030^{y}$ & $0.88 \pm 0.017^{x}$ & $<0.001$ & 0.001 \\
\hline Gizzard (\%) & Arbor Acres & $3.28 \pm 0.16^{\mathrm{z}}$ & $4.07 \pm 0.24^{y}$ & $5.80 \pm 0.29^{x}$ & $<0.001$ & 0.103 \\
\hline & Marshall & $3.46 \pm 0.13^{y}$ & $4.34 \pm 0.44^{y}$ & $6.07 \pm 0.22^{x}$ & $<0.001$ & 0.211 \\
\hline Liver (\%) & Arbor Acres & $1.58 \pm 0.04^{z}$ & $2.16 \pm 0.13^{y}$ & $3.08 \pm 0.08^{x}$ & $<0.001$ & 0.106 \\
\hline & Marshall & $1.54 \pm 0.04^{z}$ & $2.20 \pm 0.15^{y}$ & $3.12 \pm 0.14^{\mathrm{x}}$ & $<0.001$ & 0.298 \\
\hline Breast (\%) & Arbor Acres & $2.76 \pm 0.07^{\text {ay }}$ & $3.01 \pm 0.04^{y}$ & $3.69 \pm 0.14^{\mathrm{x}}$ & $<0.001$ & 0.047 \\
\hline & Marshall & $2.48 \pm 0.10^{\mathrm{bz}}$ & $3.00 \pm 0.13^{y}$ & $3.71 \pm 0.07^{\mathrm{x}}$ & $<0.001$ & 0.490 \\
\hline Yolk (\%) & Arbor Acres & $21.9 \pm 0.88^{x}$ & $19.6 \pm 0.99^{x}$ & $10.4 \pm 1.22^{\mathrm{ay}}$ & $<0.001$ & 0.011 \\
\hline & Marshall & $20.4 \pm 0.56^{\mathrm{x}}$ & $19.6 \pm 1.38^{x}$ & $7.5 \pm 0.43^{\text {by }}$ & $<0.001$ & $<0.001$ \\
\hline
\end{tabular}

a, b Means in a column are significantly different $(P<0.05)$.

$\mathrm{x}, \mathrm{y}, \mathrm{z}$ Means in a row are significantly different $(P<0.05)$.

${ }^{1}$ Days of incubation

Means $\pm \mathrm{SE}$ are presented

Glycogen content in the liver (Table 2) did not differ between AA and MS at d18, 19 and 21 of incubation $(P>0.05)$. While yolk moisture content on d 18 was significantly higher for AA compared with MS, no strain effect was observed on d 19 and 21 of 


\section{Pre-natal development and genotype differences in broilers}

incubation. Also carcass moisture content was similar between AA and MS on d 19 and 21 of incubation $(P>0.05)$. Significant reduction in moisture content was observed between $\mathrm{d} 19$ and 21 for both AA $(P<0.01)$ and $\mathrm{MS}(P<0.01)$.

Table 2: Glycogen status and moisture contents in Arbor Acres and Marshall chicks prior to hatch

\begin{tabular}{lllllll}
\hline & \multicolumn{3}{c}{ Days $^{1}$} & \multicolumn{3}{c}{ Contrasts } \\
& Strain & $18-\mathrm{d}$ & $19-\mathrm{d}$ & $21-\mathrm{d}$ & Lin & Qua \\
\hline Liver glycogen & Arbor Acres & $3.26 \pm 0.58$ & $3.49 \pm 1.90$ & $3.91 \pm 0.63$ & 0.226 & 0.867 \\
status $^{2}$ & Marshall & $2.90 \pm 0.53$ & $2.45 \pm 0.93$ & $3.54 \pm 1.74$ & 0.273 & 0.373 \\
Yolk moisture $_{\text {content }}^{3}$ & Arbor Acres & $48.2 \pm 4.1^{\mathrm{A}}$ & $49.8 \pm 2.5$ & $47.4 \pm 2.7$ & 0.596 & 0.286 \\
Carcass moisture $_{\text {content }^{3}}$ & Marshall & $41.9 \pm 2.0^{\mathrm{By}}$ & $48.3 \pm 3.3^{\mathrm{x}}$ & $48.9 \pm 2.8^{\mathrm{x}}$ & $<0.001$ & 0.051 \\
& Arbor Acres & - & $80.5 \pm 1.4^{\mathrm{x}}$ & $75.2 \pm 2.0^{\mathrm{y}}$ & 0.001 & - \\
\hline
\end{tabular}

A, B Means in a column are significantly different $(P<0.01)$.

${ }^{\mathrm{x}, \mathrm{y}}$ Means in a row are significantly different $(P<0.05)$.

${ }^{1}$ Days of incubation

${ }^{2} \mathrm{mg} / \mathrm{g}$ wet weight of liver

${ }^{3}$ as a percentage of wet weight

means $\pm \mathrm{SE}$ are presented

\section{Post-hatch assessment}

Peak ambient temperature was between $33.4 \pm 1.0^{\circ} \mathrm{C}$ and $35.4 \pm 2.0^{\circ} \mathrm{C}$, for weeks two and eight of the study period. Results for growth performance are presented in Table 3 . From day $0-28$, average daily feed intake $(\mathrm{ADFI} ; P<0.01)$ and FCR $(P<0.05)$ were higher for AA compared with MS. However, average daily gain (ADG) did not differ between the strains $(P>0.05)$.
However, for day 28 - 56, ADFI was higher in $\mathrm{MS}$ than AA $(P<0.01)$, while no difference was observed for ADG and FCR $(P>0.05)$. Averaged over days 0 - 56, ADG, ADFI and FCR did not show any statistical difference between AA and MS. Albeit, ADFI tended to be higher for MS $(P=$ 0.069). In addition, daily water intake was not significantly influenced by strain of broiler.

Table 3: Post-hatch growth performance of Arbor Acres and Marshall broilers under high ambient temperatures

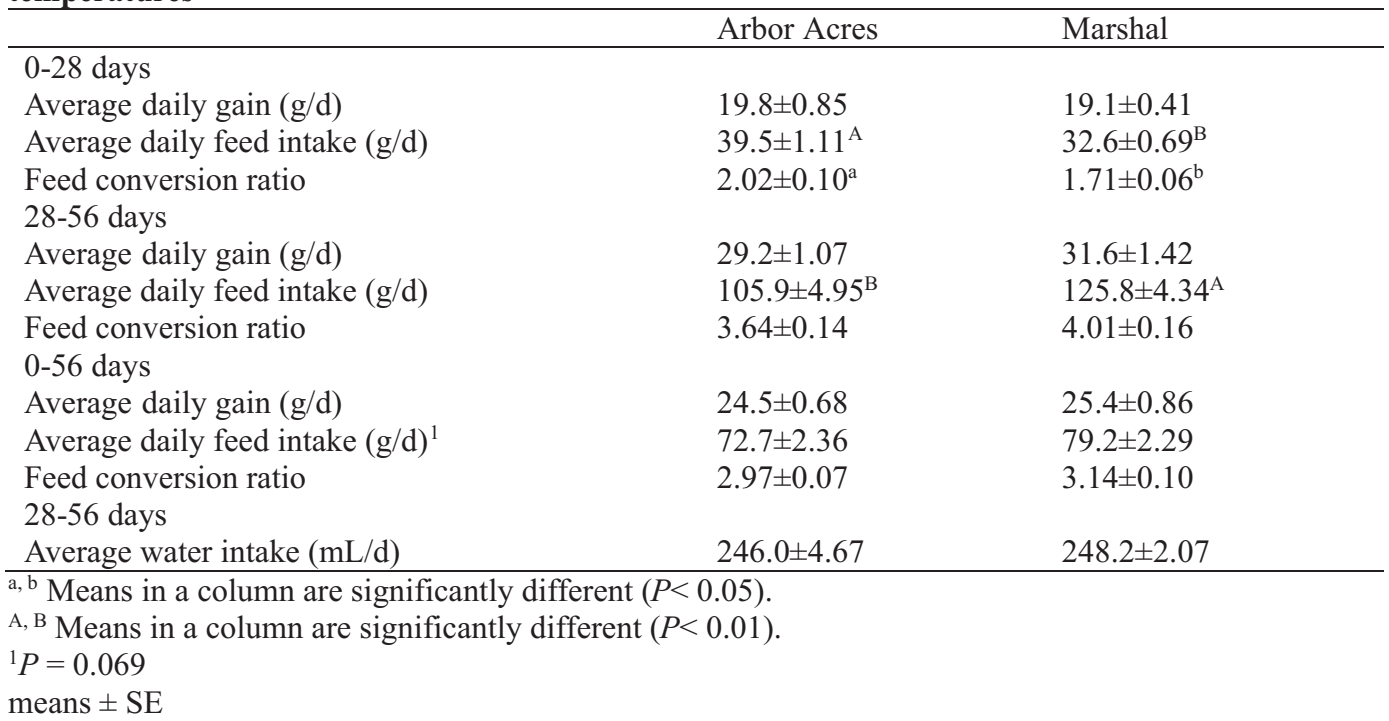




\section{Tanimowo, Adesanya and Longe}

Mean values for serum levels of $\mathrm{Na}^{+}, \mathrm{Cl}^{-}$and $\mathrm{K}^{+}$at the starter and finisher phases (Table 4) did not differ between the strains $(P>$ $0.05)$. However, between the phases, $\mathrm{Na}^{+}$, $\mathrm{Cl}$ were significantly higher at the finisher phase compared with the starter phase for both AA $(P<0.001 ; P<0.02)$ and MS $(P=$ $0.001 ; P=0.02)$. On the contrary, $\mathrm{K}^{+}$levels did not differ significantly between the starter and finisher phases.

Table 4: Serum electrolytes of two strains of broilers under high ambient temperatures

\begin{tabular}{llccl}
\hline & & Starter & Finisher & Phase \\
\hline $\mathrm{Na}^{+}$ & Arbor Acres & $105 \pm 4.0$ & $141 \pm 4.4$ & $<0.001$ \\
& Marshall & $101 \pm 7.0$ & $138 \pm 3.0$ & 0.001 \\
$\mathrm{Cl}^{-}$ & Arbor Acres & $75.1 \pm 12.6$ & $111 \pm 4.6$ & 0.025 \\
& Marshall & $72.7 \pm 8.7$ & $120 \pm 6.0$ & 0.001 \\
$\mathrm{~K}^{+}$ & Arbor Acres & $2.86 \pm 0.39$ & $3.11 \pm 0.37$ & 0.650 \\
& Marshall & $3.82 \pm 0.79$ & $3.20 \pm 0.54$ & 0.532 \\
\hline
\end{tabular}

means $\pm \mathrm{SE}$

Mean values presented in Table 5 did not reveal any significant difference in relative weights of abdominal fat, heart, kidney, liver and lungs. Relative weight of breast was however observed to be apparently higher in AA than MS $(P=0.057)$. By the end of the finisher phase, no differences were observed for relative organ weights between AA and MS $(P>0.05)$.

Table 5: Carcass characteristics at starter phase of Arbor Acres and Marshall under high ambient temperatures

\begin{tabular}{lllll}
\hline Strain & $\begin{array}{l}\text { Starter } \\
\text { Arbor Acres }\end{array}$ & Marshall & $\begin{array}{l}\text { Finisher } \\
\text { Arbor Acres }\end{array}$ & Marshall \\
\hline Live weight (g) & $437 \pm 6.0^{\mathrm{a}}$ & $412 \pm 5.9^{\mathrm{b}}$ & $1493 \pm 48$ & $1521 \pm 26$ \\
Dressed yield (\%) & - & - & $66.0 \pm 1.8$ & $64.4 \pm 0.8$ \\
Breast (\%) & $14.5 \pm 0.49$ & $13.3 \pm 0.36^{1}$ & $20.2 \pm 1.15$ & $19.0 \pm 0.52$ \\
Abdominal fat (\%) & $0.85 \pm 0.06$ & $0.97 \pm 0.11$ & $1.61 \pm 0.20$ & $1.46 \pm 0.18$ \\
Heart (\%) & $0.77 \pm 0.04$ & $0.80 \pm 0.03$ & $0.62 \pm 0.03$ & $0.59 \pm 0.04$ \\
Kidney (\%) & $1.01 \pm 0.06$ & $1.06 \pm 0.05$ & $0.75 \pm 0.04$ & $0.74 \pm 0.04$ \\
Liver (\%) & $3.40 \pm 0.27$ & $3.89 \pm 0.18$ & $2.47 \pm 0.11$ & $2.41 \pm 0.15$ \\
Lungs (\%) & $0.52 \pm 0.03$ & $0.57 \pm 0.03$ & $0.47 \pm 0.03$ & $0.54 \pm 0.03$ \\
\hline
\end{tabular}

$\frac{\mathrm{a}, \mathrm{b}}{\mathrm{a}}$ Means in a column are significantly different $(P<0.05)$.

${ }^{1} P=0.057$

\section{Discussion}

\section{Pre-hatch assessment}

The final phase of development of the avian embryo is characterised by accumulation of glycogen reserves and glycogenolysis, commencement of lung breathing and internalisation of the yolk remains into the abdomen (Cristensen et al., 1999; Moran, 2007). During this period, a cascade of changes in metabolism and physiology take place (Leksrisompong et al., 2007). In the present study, pre-natal visceral organ evaluation showed no strain differences for gizzard, heart, liver and yolk sac weights, which may connote similarities in the development of some organs. However, in this study, Arbor Acres had larger breast than Marshall, with linear increases observed as hatch-day (day 21 of incubation) approached. It was observed that between days 18 and 21 , change in relative breast weight in MS $(+49.6 \%)$ was higher than in AA $(+33.7 \%)$. A greater proportion of this increase occurred between 18 and 19 for MS. In commercial poultry meat industry, more emphasis has been on genetic selection for enlargement in the size of the pectoral muscle (Velleman, 


\section{Pre-natal development and genotype differences in broilers}

2007). These high yield meat birds may favour more caloric resources towards muscle growth than fuelling the hatching process. The breast muscle of the avian embryo is metabolically important mainly because of its relatively large size and glycogen storage capacity. The breast muscle is also the predominant source of protein mobilized to supply amino acids for gluconeogenesis if energy reserves are depleted after hatch (Keirs et al., 2002; Warner et al., 2006; De Oliveira et al., 2008). A two-fold increase in liver weight relative to weight of embryo was observed in the final phase of incubation (+95\%, AA; $+103 \% \mathrm{MS})$. This percentage change in weight was the highest of all the organs measured. Of all the organs in the embryonic body, the liver is the sole one with all metabolic pathways and enzymes active, thus accruing to it the highest metabolic activity (Krebs, 1972). According to Romanoff (1967), the liver shows extensive growth during the last phase of incubation, growing proportionately faster than the rest of the embryo to accommodate its increased metabolic demand by the late-term embryo. During periods of anaerobiosis prior to hatch, the embryonic liver is important in the production of glucose via gluconeogenesis (Scott et al., 1981; Moran, 2007). Glucose production via hepatic gluconeogenesis is the only source of glucose available to the embryo between when pipping commences and post-hatch feeding begins (Donaldson, 1995). In addition, during anaerobiosis, lactate is produced. Avian hearts lack Cori cycle enzymes to break down lactate, leaving the work of recycling to the liver during aerobic respiration Christensen et al., 2003). In this study there was a reducing trend observed for yolk weight as the day of hatch approached. It was observed that between day 18 and hatch day, Marshall embryos had utilized more than $60 \%$ of the yolk mass while Arbor Acres birds still had approximately half of the yolk content unutilized. A major proportion of the reduction in weight occurred between d 19-21 $(\approx 80 \%$ for Arbor Acres and 93\% for Marshall). Yolk constituents are mainly utilized for development of the intestine and immune system. During the incubation period, the avian embryo does not invest much metabolic resources into gut development until the end of the incubation period when rapid visceral growth and maturation occurs (Uni et al., 2003; Gilbert et al., 2007). Peebles et al. (1999) noted no difference in residual yolk sac weight through d 19 of incubation. They opined that differential uptake of the various yolk fatty acids may have occurred without causing overall changes in yolk sac weight. Embryo weight in this study did not differ between the broiler strains. This is in consonance with Dos Santos et al. (2010) who observed no difference in embryo weight relative to egg weight when considering eggs between heavy and light birds. They suggested that all embryos presented a similar developmental stage. Moisture content in our study was observed to reduce between d19 and 21 of incubation. Reduction in the relative moisture content of embryos has been found to be related to an increase in the amount of water lost from the egg (Peebles et al., 1999). Burton and Tullett (1983) proposed direct relationships between rate of egg water loss, embryonic metabolism and growth during incubation. They further stated that the rate of moisture loss during incubation is a function of the rate of metabolism in the embryo. During the course of embryonic development, the embryo experiences exponential increases in size. However, as the hatch-day approaches, growth rate decreases; due in part to a reduction in the rate of yolk content assimilation, alterations in gaseous exchange in relation to the oxygen needs of 


\section{Tanimowo, Adesanya and Longe}

the embryo as well as changes in the growth potential of the embryonic tissues (Kadam etal., 2013).

\section{Post-hatch assessment}

In the present study, exposure to high natural ambient temperatures $\left(\approx 34^{\circ} \mathrm{C}\right)$ revealed the superiority of Marshall to Arbor Acres, with lower ADFI (-17.5\%) and FCR (-15.3\%). This was however limited to the starter phase only. At the finisher phase, Marshall had significantly higher ADFI (18.8\%) than Arbor Acres, while no statistical difference could be observed for ABW and FCR. The Marshall strain of broiler is a tropically adapted strain developed for better performance under sub-optimal conditions as found in the tropics. In a study, Olawunmi et al. (2012) reported that Marshall broilers had superior body weight and gain to Arbor Acres birds at 56 days of age when exposed to heat. Amao et al. (2011) reported better performance in Ross than Marshall at 8 weeks of age. According to Razuki et al. (2007) strains that perform better under normal ambient temperature cannot maintain their superiority for growth at high ambient temperature. The negative effect of high ambient temperature is more pronounced in chicken genotypes with higher body weight and growth rate than in birds with lower body weight and growth rate (Yunisand Cahaner, 1999). Lu et al. (2007) comparing Beijing You chickens and Arbor Acres birds observed better feed efficiency in Beijing You, which would account for the maintenance of growth under hot conditions than Arbor Acres birds. The reduced productivity of birds is closely associated with the severity of heat stress and duration of exposure to high ambient temperature. In the present study, no difference in circulating levels of $\mathrm{Na}^{+}, \mathrm{Cl}$ and $\mathrm{K}^{+}$were observed between Arbor Acres and Marshall at the starter and finisher phases, when exposed to high ambient temperatures. Lin et al. (2000) reported wide variations in plasma biochemical indices; chloride content was increased by high temperature, potassium content was decreased by high or low temperature and increased by moderate temperature. Khan et al. (2002) reported that birds at high temperature showed significant difference in potassium level. In this study, serum levels of $\mathrm{Na}^{+}(\mathrm{AA},+34 \%$; $\mathrm{MS},+37 \%)$ and $\mathrm{Cl}^{-}(\mathrm{AA},+48 \%$; $\mathrm{MS},+65 \%$ ) were elevated at the finisher phase. Serum $\mathrm{K}^{+}$levels however remained relatively unchanged. Zulkifli et al. (2007) observed significantly lowered potassium levels between starter and finisher phases of heat stressed birds. They were of the opinion that birds exposed to continuous high ambient temperatures developed adaptive response to chronic heat stress, which may affect levels of blood biochemical indices. Lin et al. (2000) also reported significant difference in potassium level at $30^{\circ} \mathrm{C}$. Borges et al. (2004) also observed reduction in serum levels of metabolites in broilers exposed to high ambient temperatures. Relative weights of organs in the current study did not highlight any difference in Arbor Acres and Marshall broilers at the starter and finisher phases when exposed to high natural temperatures. Although at the starter phase Arbor Acres had apparently larger relative breast weight than Marshal. Several studies have reported significant breed differences in carcass trait (Musa et al., 2006, Ojedapo et al., 2008). Heat exposure especially has been reported to significantly reduce carcass pars of Arbor Acres birds compared with tropically adapted birds (Lu et al., 2007; Olawunmiet al., 2012).

\section{Conclusion}

The study showed that prenatal assessment of Arbor Acres and Marshal revealed existence of innate physiological differences dependent on time. Also within the last three days prior to hatch, rapid 


\section{Pre-natal development and genotype differences in broilers}

development changes of the organs occur in broiler embryos. In addition, when exposed to high ambient temperatures, the advantage of Marshall was evident at the starter phase. This advantage was however not carried on to the end of the finisher phase. The knowledge of prenatal developmental differences in broiler chicken strains will better inform studies in harnessing the benefits of peri-natal nutrition.

\section{Acknowledgement}

The authors are grateful to the Tertiary Fund (TETFund) for financial support, through the University of Ibadan.

\section{References}

Abdur-Rahman, A. A. and Abu-Dieyeh, Z. H. 2007. Effect of chronic heat stress on broiler performance in Jordan. International Journal of poultryscience, 6(1): 64-70.

Amao, S. R., Ojedapo, L. O. and Sosina O. A. 2011. Evaluation of growth performance traits in three strains of broiler chickens reared in derived savannah environment of Nigeria. World Journal of Young Researchers 1(2): 28-30.

Bennett, L. W., Keirs, R. W., Peebles, E. D. and Gerard, P. D. 2007. Methodologies of tissue preservation and analysis of the glycogen content of the broiler chick liver. Poultry Science, 86:2653-2665

Borges, S. A., Fischer da Silva, A. V., Majorka, A., Hooge, D. M. and Cummings, K. R. 2004 . Physiological responses of broiler chickens to heat stress and dietary electrolyte balance (sodium plus potassium minus chloride, milliequivalents per kilogram). Poultry Science, 83: 1551-1558.

Burton, F. G. And Tullett, S. G. 1983. A comparison of the effects of eggshell porosity on the respiration and growth of domestic fowl, duck and turkey embryos. Comparative Biochemistry and Physiology, 75(A): 167-174

Cahaner A., Deeb, N. and Settar, P. 1996. The association between broiler potential growth rate and sensitivity to heat stress. Pg 29-41

Christensen, V. L., Donaldson, W. E. and Nestor, K. E. 1999. Length of the plateau and pippingstages of incubation affects the physiology and survival of turkeys. British Poultry Science 40: 297-303.

Christensen, V. L., Ort, D. T. and Grimes, J. L. 2003. Physiological factors associated with weak neonatal poults (Meleagris gallopavo). International Journal of Poultry Science 2: 7-14

Christensen, V. L., Ort, D. T., Nestor, K. E., Velleman, S. G. and Havenstein, G. B. 2007. Genetic control of neonatal growth and intestinal maturation in turkeys. Poultry Science, 86: 476-487

De-Oliveira, J. E., Uni, Z. and Ferket, P. R. 2008. Important metabolic pathways in poultry embryos prior to hatch. World's Poultry Science Journal, 64:488-499.

Donaldson, W. E. 1995. Carbohydrate, hatchery stressors affect poult survival. Feedstuffs 67(14): 16-17

dos Santos, T. T., Corzo, A., Kidd, M. T., McDaniel, C. D., Torres Filho, R. A. and Araújo, R. F. 2010. Influence of in ovo inoculation with various nutrients and egg size on broiler performance. Journal of Applied Poultry Research, 19: 1-12

Gilbert, E. R., Li, H., Emmerson, D. A., Webb Jr, K. E. and Wong, E. A. 2007. Developmental regulation of nutrient transporter and enzyme 
mRNA abundance in the small intestine of broilers. Poultry Science. 86:1739-1753

Guerreiro, E. N., Giachetto, P. F.,Givisiez, P. E. N., Ferro, J. A., Ferro, M. I. T.,Gabriel, J. E., Furlan, R. L. and Macari, M. 2004. Brain and hepatic hsp70 protein levels in heat-acclimated broiler chickens during heat stress. Brazilian Journal of Poultry Science, 6(4): 201 - 206

Har, L. D. Rong and Zhang, Z. Y. 2000. The effect ofthermal environment on the digestion of broilers. Animal Physiology, 83: 57-64.

Jianzhen, H., Haitian, M., Liming, Y. and $\mathrm{S}$ i $\mathbf{x}$ i a $\mathrm{n} \mathbf{g}, \quad \mathrm{Z}$. 20007 . Developmentalchanges of protein profiles in the embryonic Sanhuang chicken liver. Journal of Veterinary Medicine. A Physiology Patholology and Clinical Medicine, 54:464-469.

Kadam, M. M., Barekatain, M. R., Bhanja, S. K. and Iji, P. A. 2013. Prospects of in ovo feeding and nutrient supplementation for poultry: the science and commercial applications - a review. Journal of Science, Food and Agriculture, 93: 3654-3661

Keirs, R. W., Peebles, E. D., Hubbard, S. A. and Whitmarsh S. K. 2002. Effects of supportative gluconeogenic substrates on early performance of broilers under adequate brooding conditions. Journal of Applied Poultry Research 11:367-372.

Kemp, C and Kenny, M. 2003. Feeding the modern broiler for more meat. International Hatchery Practice 17:11-13.'

Khan, W. A., Khan, A., Anjum A. D. and Rehman, Z. U. 2002. Effect of induced heat stress on some biochemical values in broiler chicks.
International Journal of Agriculture and Biology. 1560-8530:74-75.

Krebs, H. A. 1972. Some aspects of the regulation of fuel supply in omnivorous animals. Advances in Enzyme Regulation, 10: 397-420

Leksrisompong, N., Romero-Sanchez, H., Plumstead, P. W., Brannan, K. E. and Brake, J. 2007. Broiler incubation.1.effect of elevated temperature during late incubation on bodyweight and organs of chicks. Poultry Science, 86: 2685-2691

Lin, H., Du, R., Gu, X. H., Li, F. C. and Zhang Z.Y. 2000. A study on the plasma biochemical indices of heat stressed broilers. AsianAustralasian Journal of Animal ScienceVol. 13:9 Pp. 1210-1218.

Lozano, C., De Basilio, V., Oliveros, I., Alvarez, R., Colina, I., Bastianelli, D., Yahav, S. and Picard, M. 2006. Is sequential feeding a suitable technique to compensate for thenegative effects of a tropical climate in finishing broilersflAnimal Research 55:71-76.

Lu, Q., Wen, J. and Zhang, H. 2007. Effect of chronic heat exposure on fat deposition and meat quality in two genetic types of chicken. Poultry Science, 86: 1059-1064.

Moran, E. T. 2007. Nutrition of the developing embryo and hatchling. Poultry Science, 86: 1043-1049.

Musa, H. H., Chen, G. H., Cheng, J. H., Li, B. C. and Mekki, D. M. 2006. Study on carcass characteristic of chicken breeds raised under the intensive condition. International Journal of Poultry Science. 5: 530533.

Ojedapo, L. O., Akinokun O., Adedeji, T. A., Olayeni, T. B., Ameen, S. A. and Amao, S. R. 2008. Effect of strain and sex on carcass characteristics of three commercial 


\section{Pre-natal development and genotype differences in broilers}

broilers reared in deep litter system in the derived savannah area of Nigeria. World Journal of Agricultural Science, 63: 21972200.

Olawumi, S. O., Fajemilehin, S. O. and Fagbuaro, S. S. 2012. Genotype $\times$ sex interaction effects on carcass traits of three strains of commercial broiler chickens. Journal of World's Poultry Research 2(1): 21-24.

Peebles, E. D., Li, L., Miller, S., Pansky, T., Whitmarsh, S., Latour, M. A. and Gerard, P. D. 1999. Embryo and yolk compositional relationships in broiler hatching eggs during incubation. Poultry Science 78:1435-1442.

Razuki, W. M., Mukhlis, S. A. and Hamad, R. F. 2007. Performance of three commercial broiler strainsreared under hot and thermoneutral conditions. Iraqi Journal of Agriculture, 12: 92-103.

Romanoff, A. L. 1967. Biochemistry of the avian embryo; a quantitative analysis of prenatal development (Interscience Publishers, New York).

Scott, T. R., Johnson, W. A., Satterlee, D. G. and Gildersleeve, R. P. 1981. Circulating levels of corticosterone in the serum of developing chick embryos and newly hatched chicks. Poultry Science, 70: 1200-1205
Speake, B. K., Murray, A. M. and Noble, R. C. 1998. Trans port andtransformations of yolk lipids during development of the avian embryo. Progress in Lipid Research, 37:1-32.

Uni, Z., Tako, E., Gal-Garber, O. and Sklan, D. 2003. Morphological, molecular and functional changes in the chicken small intestine of the late-term embryo. Poultry Science. 82: $1747-1754$

Velleman, S. G. 2007. Muscle development in the embryo and hatchling. Poultry Science, 86; 1050-1054

Warner, J. D., Ferket, P. R., Christensen, V. L. and Felts, J. V. 2006. Effect of season, hatch time, and post-hatch holding on glycogen status of turkey poults. Poultry Science 85 (Suppl.1): 117

Yunis, R. and Cahaner, A. 1999. The effects of naked-neck $(\mathrm{Na})$ and frizzle $(F)$ genes on growth and meat yield of broilers, and their interactions with ambient temperatures and potential growth rate. Poultry Science, 78:1347-1352.

Zulkifli, I., Nwe Nwe Htin, Alimon, A. R., Loh, T. C. and Hair-Bejo, M. 2007. Dietary selection of fat by heatstressed broiler chickens. Journal of Animal Science, 2: 245-251.

Received: $20^{\text {th }}$ June, 2020 Accepted: $29^{\text {th }}$ September, 2020 